Gynecologic and

Obstetric Investigation
Gynecol Obstet Invest 2009;68:82-87

DOI: 10.1159/000215931
Received: August 28, 2008

Accepted after revision: January 19, 2009

Published online: May 6, 2009

\title{
Pregnant Women after Physical and Sexual Abuse in Germany
}

\author{
Katharina Jundt ${ }^{\mathrm{a}}$ Kristin Haertl $^{\mathrm{a}}$ Angelika Knobbe $^{\mathrm{a}}$ Ralph Kaestner ${ }^{\mathrm{a}}$ \\ Klaus Friese ${ }^{a}$ Ursula M. Peschers ${ }^{b}$ \\ a 1st Department of Obstetrics and Gynecology, Ludwig-Maximilians University Munich, and \\ ${ }^{b}$ Center for Pelvic Floor Reconstruction, Munich, Germany
}

\section{Key Words}

Pregnancy $\cdot$ Physical abuse $\cdot$ Sexual abuse $\cdot$ Symptoms of depression

\begin{abstract}
Background/Aims: The aim of our study was to evaluate the prevalence of abuse among pregnant women in Germany attending our antenatal outpatient clinic and to observe whether a history of abuse had consequences for women's feelings about their pregnancy. Methods: 455 women between the 35th and 42nd weeks of gestational age were included and were asked to fill out an anonymous questionnaire concerning their pregnancy, their actual psychological state, and their history of physical/sexual abuse. 600 questionnaires were distributed (return rate $75.8 \%$ ), 70 women (10.4\%) were excluded because of male companionship to ensure their safety in case that they were currently in an abusive relationship with the attending man. Results: 88 women (19.3\%) reported a history of sexual and/or physical abuse. Pregnant women after physical and/or sexual abuse significantly more frequently associate negative feelings with their pregnancy than nonabused women. The Hospital Anxiety Depression Scale (HADS) and the SCL-K-9 demonstrated significantly more negative feelings of depression and anxiety, strain, loneliness and less expectation of happiness for their future in abused women. Conclusion: Physical and sexual
\end{abstract}

abuse are relevant problems among women in obstetric care that may complicate their pregnancies and make them feel more depressive.

Copyright $\odot 2009$ S. Karger AG, Basel

\section{Introduction}

The prevalence of physical and sexual violence against women ranges from 8 to $40 \%$ in the literature [1]. Our own data - collected among patients attending a gynecologic outpatient clinic in Germany - showed a prevalence of sexual abuse of 20\% [2]. Abuse may cause acute and chronic injury as well as persistent stress and fear, which may be manifested in a range of physical and mental health problems.

Many women with a history of sexual abuse present with unspecific problems such as chronic pelvic pain [3]. Other possible long-term consequences are depression [4], anxiety, emotional and cognitive problems, personal dysfunction, eating and sleeping disorders, alcohol or drug abuse, relationship problems, social maladaptation, and somatizations [5]. There is also clinical evidence suggesting that women with a history of sexual abuse may be re-traumatized during pelvic examinations, vaginal ultrasounds, pregnancy, and childbirth $[6,7]$.

\section{KARGER}

Fax +4161306 1234 E-Mail karger@karger.ch www.karger.com
(C) 2009 S. Karger AG, Basel

0378-7346/09/0682-0082\$26.00/0

Accessible online at:

www.karger.com/goi
Katharina Jundt, MD

I. Frauenklinik der LMU

Maistrasse 11, DE-80337 München (Germany)

Tel. +49895160 4111, Fax +498951604166

E-Mail katharina.jundt@med.uni-muenchen.de 
Pregnant women after intimate-partner violence are known to exhibit more depressive symptoms during the pregnancy and later on [8]. Goldstein and Martin [9] found that experiencing intimate-partner physical assault was highly predictive of women's perceptions of vulnerability and loss of control in their relationships. Given that previous research has found such perceptions tied to negative health outcomes, clinicians are urged to evaluate their female patients' feelings of vulnerability as well as their experiences of intimate-partner physical assault.

The aim of our study was to evaluate the prevalence of physical and sexual abuse among pregnant women and to determine whether their feelings about the pregnancy and the course of their pregnancy were different from those of nonabused women.

\section{Material and Methods}

The study protocol was approved by the Institutional Review Board of the Medical Faculty of the Ludwig-Maximilians University, Munich, Germany.

All women who attended the antenatal outpatient clinic at the 1st Department of Obstetrics and Gynecology of the LudwigMaximilians University in Munich between April 2002 and August 2005 were asked to complete an anonymous questionnaire. The antenatal clinic provides routine obstetrical care after the 24th week of gestation.

The questionnaire was only given to women with German language ability who were not accompanied by a male; these women were excluded to ensure their safety in case that they were currently in an abusive relationship with the attending man.

The questionnaire in German language contained 5 parts: The first part was about patient characteristics such as age, marital status, parity, education, profession and nationality. The second part included general questions about the pregnancy (bleeding or nausea during pregnancy, high blood pressure, preterm labor, breast-feeding, attended medical care; previous induced abortions and miscarriages), which women could answer with 'yes' or 'no', and questions about the patients' feelings concerning their pregnancy, actual partnership and the forthcoming delivery, which women could answer with numbers from 1 (very much) to 5 (very little).

The third part of the questionnaire included a short form of the Hospital Anxiety Depression Scale (HADS). The HADS [10] and the German version HADS-D [11] are brief assessment tools consisting of distinct dimensions of anxiety and depression in non-psychiatric populations. The 14 -item questionnaire consists of two subscales measuring both levels of anxiety (HADS-D/A) and depression (HADS-D/D).

The subscales 'anxiety' and 'depression' were calculated by summing the seven item scores of the HADS-D/A and HADSD/D, respectively. Furthermore, the SCL-K-9, a short form of the SCL-90-R (Symptom Checklist-90, Revised from Derogatis) to evaluate psychological distress during the preceding week, was integrated in the questionnaire $[12,13]$.

The fourth and fifth part of the questionnaire consisted of screening questions for physical and sexual abuse. Those were modified and translated from different validated test instruments asking for child abuse and neglect and sexual abuse history. As there are no validated test instruments for child abuse and neglect in German language available, nonvalidated translations had to be used [14-16].

Physical abuse was defined as physical maltreatment with punches, bruises or fractures, including beating, slap in the face or brutal situations with physical sequelae during childhood or as an adult.

Women could rank the violence using a visual analog score from zero (not at all) to ten (extremely) and were asked for more information about age, perpetrator, frequency and lasting influence on their further life.

Sexual abuse was defined as forced sexual activity - as a child, adolescent, or adult - that the victim did not want to do, according to the Abuse Assessment Screen, McFarlane et al. [17] used in a survey by McGrath et al. [18] to screen for sexual abuse in urgent care patients. Detailed activities could be chosen: being watched naked, being touched or fondled sexually, being forced to touch the genitals of another person, being forced to have sexual intercourse, and 'others', where women could describe the special situation.

Again, women could rank the abuse using a visual analog score from zero (not at all) to ten (extremely) and were asked for more information about age, perpetrator, frequency and lasting influence on their further life

Completed questionnaires were left in a specially marked and secure box located in the waiting room. A daily log was kept of the number of questionnaires distributed and returned. A female gynecologist and a female psychologist were available on site in case a woman became distressed while completing the questionnaire. As well, women were provided with the names and telephone numbers of these professionals in case they wanted to access their services at a later date.

The data were analyzed using the Statistical Package for Social Sciences (SPSS Inc., Chicago, Ill., USA), Version 12.0. Frequencies were calculated for dichotomous data and analyzed by a $\chi^{2}$ test. Ordinal data were analyzed by a Mann-Whitney U test. Numerical data were analyzed using a t test for independent samples.

\section{Results}

455 of 600 distributed questionnaires were returned (return rate: $75.8 \%$ ). Since women accompanied by a male were excluded as mentioned above, our study group was pre-selected and excluded 70 women (10.4\%) with German language ability (70 women out of 670$) .88$ women (19.3\%) reported a history of sexual and/or physical abuse and 367 women $(80.7 \%)$ had no history of abuse. Mean age of the abused women was 32.3 years (standard deviation (SD): 5.3 years), of the nonabused women 33.1 years (SD: 6.3 years). Both groups showed 
no significant differences concerning demographic data (e.g. week of gestation, marital status, parity, education, profession and nationality). There were also no differences in the educational and social status of women in the two groups.

From the 88 abused women, physical abuse was sustained by $18(20.5 \%)$ women as an infant ( $0-5$ years), 20 (22.7\%) as a schoolchild (6-12 years), 22 (25.0\%) during adolescence (13-18 years), 14 (15.9\%) during adulthood (19+ years), and 19 (21.6\%) during multiple stages. Sexu-

Table 1. Abusive situations and perpetrators (more than one answer possible): $\mathrm{n}=88$ (in \%)

\begin{tabular}{|c|c|c|c|}
\hline \multicolumn{2}{|l|}{ Abusive situations } & \multicolumn{2}{|c|}{ Perpetrator } \\
\hline \multicolumn{4}{|l|}{ Sexual abuse } \\
\hline Being watched naked & $10(11.4)$ & spouse & $11(12.5)$ \\
\hline \multicolumn{4}{|l|}{ Being touched or fondled } \\
\hline sexually & $47(53.4)$ & father & $10(11.4)$ \\
\hline \multicolumn{4}{|l|}{ Being forced to touch other } \\
\hline person's genitals & $13(14.8)$ & mother & 0 \\
\hline \multicolumn{4}{|l|}{ Being forced to have sexual } \\
\hline intercourse & $16(18.2)$ & relative & $2(2.3)$ \\
\hline \multirow[t]{2}{*}{ Others } & $10(11.4)$ & friend & $22(25.0)$ \\
\hline & & stranger & $23(26.1)$ \\
\hline Total number of women & $64(72.7)$ & multiple & $7(8.0)$ \\
\hline \multicolumn{4}{|l|}{ Physical abuse } \\
\hline Repeatedly beating & $33(37.5)$ & spouse & $15(17.0)$ \\
\hline Brutal situation & $10(11.4)$ & father & $20(22.7)$ \\
\hline Physical abuse & $1(1.1)$ & mother & $11(12.5)$ \\
\hline \multirow[t]{3}{*}{ Others } & $8(9.1)$ & relative & $5(5.7)$ \\
\hline & & friend & $10(11.4)$ \\
\hline & & stranger & $5(5.7)$ \\
\hline Total number of women & $47(53.4)$ & multiple & $16(18.2)$ \\
\hline
\end{tabular}

al abuse was suffered by 10 (11.4\%) women as an infant, $16(18.2 \%)$ as a schoolchild, $30(34.1 \%)$ during adolescence, 25 (28.4\%) during adulthood and 16 (18.2\%) during multiple stages.

The numbers of different abusive situations and perpetrators are given in table 1.

$61.7 \%$ of the abused women explained that the abusive situation had a lasting influence on their further life and ranked the situation with more than 5: visual analog score reaching from zero (no influence) to ten (severe influence).

Evaluation of the second part of the questionnaire showed that nausea and vomiting during pregnancy was significantly more frequent among abused women (59.1 vs. $43.4 \%$ ) than nonabused women. Abused women felt significantly less pleasure about their child and thought that the child was making life more difficult and that the child was less of an enrichment for their life. In addition, abused women had a less close relationship to their mothers and fathers than nonabused women and the pregnancy was significantly more seldom planned (table 2, only questions with significant differences are shown).

The Hospital Anxiety Depression Scale (HADS) to evaluate symptoms of anxiety and depression and the SCL-K-9 demonstrated significantly more feelings of depression and anxiety, strain, loneliness, vulnerability and less expectation of happiness for their future in abused women. The subscale HADS-D/D (for depression) and HADS-D/A (for anxiety) consists of 7 items each and sum up to 21 in maximum each. A value greater or equal than 11 was considered as conspicuous (11-14 as 'severe' and 15-21 as 'very severe'). The detailed results are shown in table 3.

Table 2. Questions concerning pregnancy

\begin{tabular}{|c|c|c|c|c|c|c|c|}
\hline & Groups & $\begin{array}{l}1 \\
\text { (very much) }\end{array}$ & 2 & 3 & 4 & $\begin{array}{l}5 \\
\text { (very little) }\end{array}$ & $\begin{array}{l}\mathrm{p} \text { value } \\
(<0.05)\end{array}$ \\
\hline \multirow[t]{2}{*}{ Are you happy with your child? } & abused $(\mathrm{n}=88)$ & 71.6 & 22.7 & 4.5 & 1.1 & - & \multirow[t]{2}{*}{$<0.001$} \\
\hline & nonabused $(\mathrm{n}=367)$ & 87.7 & 10.6 & 0.3 & 0.3 & 1.1 & \\
\hline \multirow[t]{2}{*}{ Does the child make your life more difficult? } & abused $(\mathrm{n}=88)$ & 1.2 & 15.1 & 23.3 & 24.4 & 36.0 & \multirow[t]{2}{*}{0.002} \\
\hline & nonabused $(\mathrm{n}=367)$ & 1.9 & 4.4 & 16.1 & 26.2 & 49.0 & \\
\hline \multirow[t]{2}{*}{ Does your child enrich your life? } & abused $(\mathrm{n}=88)$ & 57.5 & 25.3 & 14.9 & 1.1 & 1.1 & \multirow[t]{2}{*}{0.034} \\
\hline & nonabused $(\mathrm{n}=367)$ & 67.5 & 24.9 & 5.6 & 0.8 & 1.1 & \\
\hline \multirow[t]{2}{*}{ Was this pregnancy planned? } & abused $(\mathrm{n}=88)$ & 42.9 & 15.5 & 11.9 & 10.7 & 19.0 & \multirow[t]{2}{*}{0.043} \\
\hline & nonabused $(\mathrm{n}=367)$ & 54.9 & 16.6 & 7.6 & 3.1 & 17.7 & \\
\hline
\end{tabular}

Mann-Whitney $U$ test, frequencies in percent, possible answers with numbers from 1 (very much) to 5 (very little). 
Table 3. Results of the HADS-D

\begin{tabular}{|c|c|c|c|c|}
\hline & \multicolumn{2}{|c|}{ HADS-D/D (depression) } & \multicolumn{2}{|c|}{ HADS-D/A (anxiety) } \\
\hline & mean $\pm \mathrm{SD}$ & $\begin{array}{l}\geq 11 \text { (conspicuous) } \\
\mathrm{n} \text { ( } \% \text { of group) }\end{array}$ & mean $\pm S D$ & $\begin{array}{l}\geq 11 \text { (conspicuous) } \\
\mathrm{n} \text { ( } \% \text { of group) }\end{array}$ \\
\hline Abused $(\mathrm{n}=88)$ & $8.27 \pm 1.84$ & $7 / 88(8.0)$ & $8.73 \pm 2.55$ & $19 / 88(21.6)$ \\
\hline Non-abused $(\mathrm{n}=367)$ & $6.82 \pm 2.43$ & $12 / 367(3.3)$ & $7.57 \pm 2.56$ & $45 / 367(12.3)$ \\
\hline $\mathrm{p}$ value & $\leq 0.01^{*}$ & $0.048^{\#}$ & n.s. ${ }^{*}$ & $0.023^{\#}$ \\
\hline
\end{tabular}

HADS-D = Hospital anxiety and depression scale in German; D = depression; $\mathrm{A}=$ anxiety; $\mathrm{SD}=$ standard deviation; n.s. = not significant.

* $\mathrm{t}$ test for independent values (abused vs. nonabused); ${ }^{*} \chi^{2}$ test (abused vs. nonabused).

\section{Discussion}

To our knowledge this is the first study evaluating physical and sexual abuse among pregnant women in a large German population. Furthermore, our study shows that pregnant women with a history of physical and/or sexual abuse significantly more frequently associate the pregnancy with negative feelings than nonabused women. They (more often) consider the pregnancy as a burden and see the child making their everyday life (concerning financial problems or partnership) more difficult.

The Hospital Anxiety Depression Scale (HADS-D) and the SCL-K-9 also demonstrated significantly more negative feelings of depression and anxiety, strain, loneliness and less expectation of happiness for their future in abused women.

In those women, violence exposure induced partially negative attitudes to their pregnancy, which can lead to a wide spectrum of problems during pregnancy or delivery: women may avoid attending the obstetrical care (e.g. to avoid vaginal examinations or presenting their bruises), they might neglect problems with their pregnancy, and depression as well as anxiety can lead to alcohol and drug abuse. All these factors may result in known obstetric complications among abused women: such as hypertension, premature rupture of membranes and anemia, increased risk for low-birth-weight infants, preterm delivery, and neonatal death $[19,20]$.

A study by Talbot et al. [21] in a medical health care centre confirmed our findings that women with a history of sexual abuse tend to develop depressive symptoms. McFarlane et al. [22] found that women after sexual assault reported significantly higher levels of PTSD (posttraumatic stress disorder) symptoms compared with non-sexually assaulted women. They could also show that the risk of re-assault decreased if contact was made with health or justice agencies.

A study by Lang et al. [23] showed that pregnant women who had experienced sexual abuse and emotional neglect exhibited more psychopathology during pregnancy: in addition, emotional neglect as well as physical abuse predicted poorer maternal outcomes 1 year postpartum. Contrary to their expectations, physical abuse was related to less aggression during pregnancy, and emotional abuse was associated with less pathology postpartum. A routine screening for abuse in the maternity services setting was proposed by Guo et al. [24] to decrease the effect of abuse on women and their children. The high prevalence of physical and/or sexual abuse found in our study confirms the usefulness of this procedure.

Because of the anonymity of our questionnaires we were not able to follow up the pregnant and abused women during their delivery. For most women delivery represents an extreme situation. It is generally impossible to predict how somebody will react during extreme pain or fear. Women with PTSD (post-traumatic stress disorder) after sexual abuse might extremely feel to be at the mercy of obstetricians or nurses. The childbirth is often associated with feelings of anxiety. Vaginal examinations by (frequently male) obstetricians cannot be performed as routinely as in other women, as they could trigger a re-traumatization. Abused women often cannot accept the 'routine' disturbances during the childbirth with coming and going of the nurses, midwives or doctors. They need constant care they can rely on, that gives them a feeling of confidence and security. In Germany, education about sexual violence is neither part of the medical-school curriculum nor part of the training for residents in any subspecialty. Clinicians do not have clear guidelines about how to identify, treat, or counsel 
a woman with a history of sexual abuse. Therefore, it is necessary to design a special training program for midwives and physicians working with pregnant women [25]. This was done before by an Australian group who developed a program which increased the self-reported comfort and competency of health professionals to identify and care for women with psychosocial issues such as domestic violence, past sexual abuse and concerns about caring for the baby [26].

Our study also shows that apart from negative or depressive feelings, nausea and vomiting during pregnancy was more frequent among abused women and that the number of induced abortions (17\%) or miscarriages (28\%) was significantly higher among abused women compared to nonabused controls (about twice as high). This result agrees with data from Fisher et al. [27] who examined women presenting for repeated induced abortion and found it - among other factors - to have an association with sexual and physical abuse. They recommend screening for a current or past history of relationship violence and sexual abuse among women presenting for repeated abortion.

Sexual and physical abuse do not represent a social side issue. In the collective of our present study, 19\% of pregnant women reported to have been physically and/or sexually abused at least once in their life. This is in agreement with our earlier presented data where about $20 \%$ of the women attending a gynecological outpatient clinic were abused at least once in their life [2]. Apart from this, women with an overactive-bladder syndrome suffered from an abusive situation in more than $30 \%$ in comparison to continent women or patients with stress urinary incontinence [28].

Therefore, physical and sexual abuse should be taken into account as relevant differential diagnosis especially in women with 'conspicuous' behavior, e.g. hesitation to undress, unpersuasive explanations of bruises on the body, repulsing behavior during the vaginal examination or ultrasound, or, on the other hand, sexually provocative behavior. Physicians should also consider that any kind of gynecological examination in these women could trigger a flash-back of the primary situation and re-traumatize the concerned women [29]. Our findings concerning the perpetrator of sexual abuse also concur with our previously published data that abused women know their offender in more than $70 \%$ of cases.

A possible bias of our study might be the selected study population: only women without male companionship were asked to participate in our survey. The latter women were excluded to ensure their safety in case that they were currently in an abusive relationship with the attending man. Thus, our data may under- or overestimate the number of women seeking obstetric care with a history of physical and/or sexual abuse: on the one hand, abused women might be excluded, on the other hand, the selection of included women may be biased towards those with partner problems, low social support or women who were single parents. However, since the large majority (about 90\%) of all women attended the outpatient clinic without male companionship, the possible bias due to this exclusion criterion can be expected to be relatively small and should not substantially influence our general results.

A second limitation of our study is that data were collected in a large, economically prosperous urban center and, as such, are not representative of the general German population. Furthermore, our study is exclusively based on self-reported data concerning physical and sexual abuse. The part of the questionnaire used to evaluate the history of abuse and the feelings about pregnancy is not validated. There is no validated questionnaire on these issues available in German. Finally, as 'physical and sexual abuse' is a very intimate and emotional subject, one could criticize that questionnaire data do not measure the subjective view of the women in a comprehensive way. Semi-structured interview data would have been an additional tool to complement the quantitative data.

In conclusion, our results show that physical and sexual abuse are relevant problems among women in obstetrical care that make them feel more depressive and may complicate their pregnancies. Clinicians must be aware that those abused women cannot be treated 'routinely'. They need special care during their pregnancy and sensitive treatment during delivery. As clinicians do not have clear guidelines about how to identify, treat, or counsel a woman with a history of sexual abuse, it is necessary to design a special training program for midwives and physicians working with those pregnant women. Furthermore, the high occurrence of abuse in this selected study population with a wide spectrum of symptoms indicates that abuse must generally be taken into account as a relevant differential diagnosis. 


\section{References}

1 Hilden M, Schei B, Swahnberg K, Halmesmaki E, Langhoff-Roos J, Offerdal K, Pikarinen $U$, Sidenius $K$, Steingrimsdottir $T$, Stoum-Hinsverk H, Wijma B: A history of sexual abuse and health: a Nordic multicentre study. BJOG 2004;111:1121-1127.

2 Peschers UM, DuMont J, Jundt K, Pfuertner M, Dugan E, Kindermann G: Prevalence of sexual abuse among women seeking gynecologic care in Germany. Obstet Gynecol 2003; 101:103-108.

3 Lampe A, Solder E, Ennemoser A, Schubert C, Rumpold G, Sollner W: Chronic pelvic pain and previous sexual abuse. Obstet Gynecol 2000;96:929-933.

4 Buzi RS, Weinman ML, Smith PB: The relationship between adolescent depression and a history of sexual abuse. Adolescence 2007; 42:679-688.

5 Poleshuck EL, Dworkin RH, Howard FM, Foster DC, Shields CG, Giles DE, Tu X: Contributions of physical and sexual abuse to women's experiences with chronic pelvic pain. J Reprod Med 2005;50:91-100.

6 Mayer L: The severely abused woman in obstetric and gynecologic care: guidelines for recognition and management. J Reprod Med 1995;40:13-18.

7 Weijenborg PT, de Koning BA, van Roosmalen GJ: Individualized obstetrical care for women with a history of sexual abuse. Ned Tijdschr Geneeskd 2001;145:393-396.

8 Martin SL, Li Y, Casanueva C, Harris-Britt A, Kupper LL, Cloutier S: Intimate partner violence and women's depression before and during pregnancy. Violence Against Women 2006;12:221-239.

9 Goldstein KM, Martin SL: Intimate partner physical assault before and during pregnancy: how does it relate to women's psychological vulnerability? Violence Vict 2004;19: 387-398.

10 Zigmont AS, Snaith RP: The hospital anxiety and depression scale. Acta Psychiatr Scand $1983 ; 67: 361-370$
11 Herrmann Ch, Buss U, Snaith RP: Hospital Anxiety and Depression Scale - Deutsche Version HADS-D: Ein Fragebogen zur Erfassung von Angst und Depressivität in der somatischen Medizin - Testdokumentation und Handanweisung. Bern, Huber, 1995.

12 Franke GH: SCL-90-R. Symptom-Checkliste von L.R. Derotatis. Deutsche Version, ed 2. Göttingen, Beltz Test, 2002.

13 Klaghofer R, Brähler E: Konstruktion und teststatistische Prüfung einer Kurzform der SCL-90-R. Z Psychol Psychiatr Psychother 2001:49:115-124.

14 Bernstein PD, Fink L, Handelsmann L, Foote J, Lovejoy M, Wenzel K, Sapareto E, Ruggiero J: Initial reliability and validity of a new retrospective measure of child abuse and neglect. Am J Psychiatry 1994;151:1132-1136.

15 Griffith Pl, Myers RW, Cusick GM, Tankersley MJ: MMPI-2 profiles of women differing in sexual abuse history and sexual orientation. J Clin Psychol 1997;53:791-800.

16 Schäfer M, Schnack B, Soyka M: Sexueller und körperlicher Missbrauch während früher Kindheit und Adoleszenz bei späterer Drogenabhängigkeit. Psychother Psychosom Med Psychol 2000;50:38-50.

17 McFarlane J, Parker B, Soeken K, Bullock L: Assessing for abuse during pregnancy: severity and frequency of injuries and associated entry into prenatal care. JAMA 1992 267:3176-3178.

18 McGrath ME, Hogan JW, Peipert JF: A prevalence survey of abuse and screening for abuse in urgent care patients. Obstet Gynecol 1998;91:511-514

19 Kaye DK, Mirembe FM, Bantebya G, Johansson A, Ekstrom AM: Domestic violence during pregnancy and risk of low birthweight and maternal complications: a prospective cohort study at Mulago Hospital, Uganda Trop Med Int Health 2006;11:1576-1584

20 Sarkar NN: The impact of intimate partner violence on women's reproductive health and pregnancy outcome. J Obstet Gynaecol 2008;28:266-271.
21 Talbot NL, Conwell Y, O'Hara MW, Stuart S, Ward EA, Gamble SA, Watts A, Tu X: Interpersonal psychotherapy for depressed women with sexual abuse histories: a pilot study in a community mental health center. J Nerv Ment Dis 2005;193:847-850.

22 McFarlane J, Watson K, Gist J, Batten E, Hall I, Smith S: Intimate partner sexual assault against women: frequency, health consequences, and treatment outcomes. Obstet Gynecol 2005;105:99-108.

23 Lang AJ, Rodgers CS, Lebeck MM: Associations between maternal childhood maltreatment and psychopathology and aggression during pregnancy and postpartum. Child Abuse Negl 2006;30:17-25.

24 Guo SF, Wu JL, Qu CY, Yan RY: Physical and sexual abuse of women before, during, and after pregnancy. Int J Gynaecol Obstet 2004; 84:281-286.

25 Mezey G, Bacchus L, Bewley S, White S: Domestic violence, lifetime trauma and psychological health of childbearing women. BJOG 2005;112:197-204

26 Gunn J, Hegarty K, Nagle C, Forster D, Brown S, Lumley J: Putting woman-centered care into practice: a new (ANEW) approach to psychosocial risk assessment during pregnancy. Birth 2006;33:46-55.

27 Fisher WA, Singh SS, Shuper PA, Carey M, Otchet F, MacLean-Brine D, Dal Bello D, Gunter J: Characteristics of women undergoing repeat induced abortion. CMAJ 2005; 172:637-641.

28 Jundt K, Scheer I, Schiessl B, Pohl K, Haertl K, Peschers UM: Physical and sexual abuse in patients with overactive bladder: is there an association? Int Urogynecol J Pelvic Floor Dysfunct 2007; 18:449-453.

29 Menage J: Women's perception of obstetric and gynaecological examinations. BMJ 1993; 306:1127-1128. 